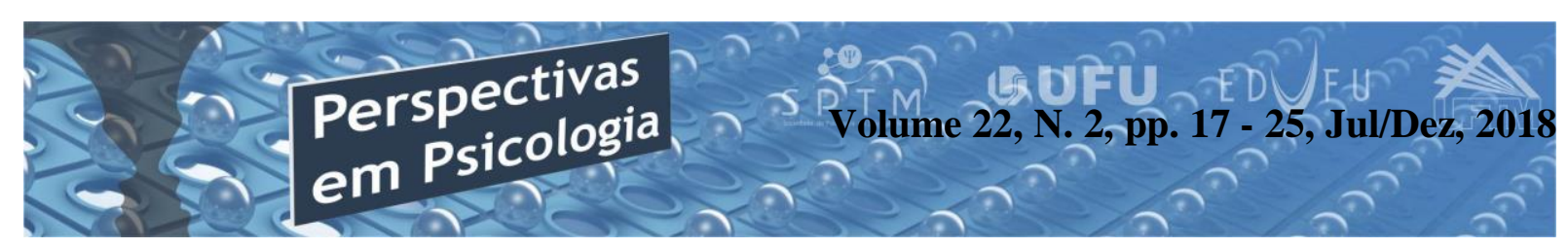

\title{
O PSICÓLOGO E AS DOENÇAS NEURODEGENERATIVAS NA INFÂNCIA
}

\author{
Thayse Maria Ferreira Dules Silva \\ (Faculdade de Ensino Regional Alternativa - FERA - Arapiraca - AL)
}

\begin{abstract}
Resumo
É relatada a experiência de uma psicóloga frente a doenças neurodegenerativas na infância no setor de neuro estimulação de uma instituição de reabilitação. Trata-se de uma pesquisa qualitativa, amparada pelos pressupostos teórico-metodológicos da Neurociência, relatando a experiência profissional diante de dois casos específicos. O profissional de psicologia precisa ter traquejo teórico metodológico para lidar com as diversas nuances de atendimentos complexos com a facticidade da morte presente sem, no entanto, distanciar-se de sua natureza humana elaborando seus próprios lutos reconhecendo suas limitações diante de doenças progressivas que culminarão na maioria das vezes na morte do seu paciente.
\end{abstract}

Palavras-Chave: Psicologia; Morte; Doenças Progressivas.

\section{Abstract \\ Psychologist and neurodegenerative diseases in childhood}

The experience of a psychologist on childhood neurodegenerative diseases in the neuro stimulation sector of a rehabilitation institution is reported. This is a qualitative research, supported by the theoretical-methodological assumptions of Neuroscience, reporting the professional experience in two specific cases. The psychology professional must have a theoretical methodological approach to deal with the various nuances of complex attendance with the facticity of the present death without, however, distancing himself from his human nature by elaborating his own mourning, recognizing his limitations in face of progressive illnesses that will culminate in the death of his patient.

Keywords: Psychology; Death; Progressive Diseases.

\section{Introdução}

O interesse em relatar a experiência intitulada, $\mathrm{O}$ psicólogo frente a doenças neurodegenerativas na infância: Uma experiência diante de doenças progressivas e a morte, surgiu mediante as vivências experienciadas durante o trabalho de estimulação neuro-sensorial realizado em uma instituição de reabilitação física e intelectual no município de Arapiraca Alagoas.

Essa experiência despertou a iniciativa de relatar enquanto psicóloga o impacto na vida profissional em ter que 
lidar com crianças em processo progressivo de uma doença neurológica incurável e sua consequente morte, além de ter que lidar com as mudanças na vida dos familiares desde o diagnostico, tratamento e morte desses entes. Torna-se interessante relatar qual a visão do profissional ao conviver com a realidade de atendimentos marcados pelo sofrimento psicológico vivido por crianças e familiares destas que apresentam o quadro clínico supra, devido às mudanças severas causadas em suas vidas geradas pelo adoecimento das mesmas.

Quando se fala em doenças neurodegenerativas infantis temos que lembrar que as mesmas compõem um grupo variado de entidades em que os erros inatos do metabolismo induzem a defeitos enzimáticos intrínsecos às células com eventual acúmulo de material intracelular. É um processo irreversível e quanto mais avançam os estudos científicos sobre o assunto mais descobertas são realizadas sobre a diversidade de patologias que essa destruição neurológica causa ao organismo. A cura da maioria dessas patologias é pouco provável e os tratamentos escassos, o que leva a morte das pessoas diagnosticadas com essas doenças antes do início da fase adulta (Torres et al., 1997).

Todas as patologias neurodegenerativas englobam um tratamento específico a favor da melhor qualidade de vida possível, no entanto não é nulo o fato de que pode gerar estresse, trazendo sinais e sintomas como: apatia, depressão, desânimo, sensação de desalento, hipersensibilidade emotiva, raiva, ansiedade e irritabilidade (Lorencetti e Simonetti, 2005). Com os avanços terapêuticos, muitas pessoas acometidas pela doença passaram a ter a possibilidade de se tratarem em casa, logicamente com acompanhamento clínico, ou até mesmo realizar seus ciclos terapêuticos nos hospitais, mas podendo voltar para casa no mesmo dia, sendo esta uma comodidade proporcionada pelo avanço científico.

No entanto, a depender do estágio da doença e a depender de alguns fatores de risco que a pessoa foi exposta, ela irá precisar de cuidados mais intensos, de maneira que os procedimentos terapêuticos podem ser realizados de forma composta, o que geralmente ocorre na maioria dos casos, ou ainda as pessoas terem que ser hospitalizadas por algum período e, com isso, alguns fatores que desencadeiam certos estressores estarão presentes, como o afastamento da família e de sua rotina, além da despersonificação, perda do controle das situações e muitas vezes do poder de decisão (Imanishi \& Silva, 2016).

O homem dificilmente irá encarar abertamente o seu fim, apenas eventualmente com certo temor é que 
cogitará a possibilidade de sua própria morte, fato que ocorrerá possivelmente ao se deparar com uma doença que ameaça sua vida. No entanto, o adoecer reflete para o individuo, a família e o profissional a verdade irrefutável da não invencibilidade do homem, além da racionalização das suas fraquezas e limites na fase mais avançada da doença, também chamada de fase terminal, em que a pessoa se depara com a realidade de sua existência humana, a finitude.

Desse modo, Kovács (1992) afirma que o medo da morte é temido de formas diferentes, considerando os diferentes níveis de desenvolvimento da pessoa acometida pela doença. A criança tem medo da morte, mas crê que pode desfazêla, no entanto, à medida que o desenvolvimento se processa, ela passa a compreender que a morte é irreversível, e esta passa a ser aterrorizante. Diante do que foi exposto, faz-se imprescindível uma atenção considerável às dores sofridas por essas pessoas que estão nesta fase, dores referentes a cunhos múltiplos, como já foi discutido. Assim, deve-se ter uma sensibilidade aos desejos, preocupações e aos medos da pessoa em fase final, sendo a desesperança, a morte e o morrer questões a serem trabalhadas por um profissional que deverá ter essa competência de lidar com as dores subjetivas e objetivas da pessoa em processo de adoecimento e morte, propiciando-lhe conforto e alívio no seu momento final, e este encargo cabe aos profissionais da Psicologia.

Para tanto, se faz importante estudar quais são os impactos na vida de uma criança com uma doença rara neurodegenerativa e buscar compreender quais as dificuldades e a importância do atendimento psicológico as crianças e aos familiares destas durante o processo de adoecimento. Diante desse contexto desafiador, torna-se essencial a produção de novos conhecimentos para nortear algumas posturas dos profissionais de Psicologia e outros profissionais da saúde.

\section{Método}

\section{Experiência investigada}

Este estudo aborda de forma longitudinal, descritiva e exploratória, a vivência de uma psicóloga dentro de um enfoque de pesquisa qualitativa apoiada no referencial teórico da Neuropsicologia e da Neurociência (Cagnin, 2010). A natureza investigativa da Neuropsicologia merece aqui destaque, pois são as hipóteses teoricamente guiadas que fornecem a linha base norteadora na pesquisa, avaliação e reabilitação neuropsicológicas. Optou-se pela adoção dessa estratégia metodológica por que a mesma possibilita uma 
compreensão particular do objeto de estudo a partir da percepção da pessoa (o profissional) que vivencia uma dada situação (a função de observador, e agente dentro caso). Sendo assim, este é um estudo de caráter fenomenológico acerca de uma experiência profissional na área da neuropsicologia clínica.

Atualmente existe uma interação crescente entre neurociência e psicologia clínica. É possível observar que algumas escolas psicoterápicas procuram incorporar o conhecimento produzido pela neurociência às suas teorias, e ao mesmo tempo, a neurociência busca também subsídios na psicologia clínica, para compreender como e quais intervenções psicoterapêuticas têm a capacidade de aliviar determinados transtornos mentais (Callegaro e Landeira-Fernandez, 2007). A psicologia e suas intervenções psicoterapêuticas atuam no tecido neural, sendo capaz de criar mudanças no padrão de comunicação sináptica, efeito esse que é similar à forma como as drogas psicotrópicas agem no organismo. Logo, o sistema nervoso central constitui o local comum às intervenções psicológicas e farmacológicas.

\section{Casos citados}

Dois casos clínicos de uma instituição de reabilitação física e intelectual na cidade de Arapiraca, Alagoas serão discutidos, os mesmos sofrem de alguma doença neurodegenerativa. Matheus, onze anos, esteve em tratamento na instituição durante seis anos, foi diagnosticado aos cinco anos com a ataxia rara de Freidreich. José de sete anos de idade é acompanhado pela instituição desde os três, a criança foi diagnosticada com Ataxia de Duchenne. Na perspectiva assumida por este estudo - o postulado de que o observador não é neutro, é considerado também um participante -, incluímos nesse cenário Thayse, psicóloga clínica com 2 anos de experiência na área de estimulação e reabilitação neuropsicológica. À exceção da profissional, todos os outros nomes citados são fictícios em respeito às disposições éticas.

\section{Instrumento e coleta de dados}

Utilizou-se o diário de campo, uma espécie de "diário de bordo" no qual o observador anota, dia após dia, com estilo telegráfico, os eventos da observação, documentando a progressão da pesquisa (Beaud \& Weber, 1998). É o relato escrito daquilo que o investigador vê, ouve, experiencia, sente e pensa no decurso da coleta de dados. Esta investigação colocou em foco a experiência do observador, sistematizada em anotações de diário de 
campo. Esse diário continha os relatos escritos das observações realizadas ao longo de um ano de trabalho na referida instituição de setembro de 2015 a agosto de 2016. Os registros foram elaborados logo após as observações. Ao desenvolver esses relatos, manteve-se a atenção aos pressupostos do método de observação utilizado, que afirma que é interessante que o observador reserve lugar para a sua vivência pessoal e não apenas forneça um relatório descritivo e superficial a respeito do que aconteceu (relato dos fatos, do que foi visto, do que foi ouvido).

\section{Procedimento de análise dos dados}

Nesse estudo foi utilizada uma abordagem qualitativa, pois o maior interesse era entender os processos, ou seja, saber como os fenômenos ocorrem naturalmente e como são as relações estabelecidas entre esses fenômenos. A abordagem qualitativa nada mais é do que o estudo de significados, significações, ressignificações, representações psíquicas, representações sociais, simbolizações, simbolismos, percepções, pontos de vista, perspectivas, vivências, experiências de vida e analogias. Tem abordado, entre outros temas: mecanismos de adaptação; adesão e não adesão a tratamentos; estigma; cuidados; reações e papéis de cuidadores profissionais e familiares; fatores facilitadores e dificuldades frente à profissão / frente ao tratamento / frente às condições de trabalho (Turato, 2003).

\section{Desenvolvimento dos casos}

Matheus passou por uma rotina extensa de acompanhamento com uma equipe multiprofissional, em estado avançado da doença, quadro clínico progressivo, de cadeira de rodas, não anda desde os seis anos, com escoliose severa sente dores constantes, dificuldade para respirar e falar, no que concernem aspectos psicológicos tem dificuldades em lidar com frustração, quando se decepciona apresenta crises de choro, não aceita nem um estímulo que lhe proporcione desafios, pois não suporta lidar com suas perdas, mesmo que seja fictício, por exemplo um jogo. Sua fala é bastante pontual devido a dificuldade em respirar limitando assim, ainda mais a sua expressividade, Matheus mostra-se inconformado e por vezes nega sua própria situação. A cuidadora relata por vezes aos terapeutas que a criança está cada vez mais "aleijada", tocando-o e mostrando as deformidades do corpo do neto, isso leva a criança a um estado depresso, até porque seu cognitivo consciente está intacto e o mesmo tem uma ótima compreensão do que ocorre ao seu redor.

Os atendimentos de Matheus no processo de reabilitação tinham foco na 
qualidade de vida da criança, muitos atendimentos eram realizados em conjunto com a terapeuta ocupacional para poder favorecer um melhor posicionamento e para na união dos saberes criarmos um ambiente propício para a neuro estimulação.

Diversas foram às situações em que foi necessário confrontá-lo com suas frustrações e decepções para que o mesmo entrasse em contato com sua problemática e assim elaborasse seus sentimentos, que por vezes eram de negação da sua condição física, choro e irritabilidade, talvez essa fosse a forma de negar suas mortes, pois como afirmam alguns autores, o ser humano nega suas experiências dolorosas, tais como as mortes do cotidiano (Medeiros e Lustosa 2011). O traquejo das emoções da criança favorecido durante as sessões, permitia a expressividade dessas angustias internas em relação ao seu processo de adoecimento de maneira que a criança entrasse numa busca de homeostase, substituindo o comportamento voluntarioso por um comportamento colaborativo viabilizando a aceitação das atividades propostas permitindo que o processo de neuro estimulação tivesse andamento, garantindo a manutenção dos aspectos cognitivos. É importante ressaltar que os atendimentos acabavam se estendendo ao cuidador também em forma de orientação e acolhimento.
Como de praxe, as doenças neurodegenerativas, como a ataxia de Freidreich, condição neurobiológica de Matheus, leva a morte. Depois de alguns meses de atendimento recebemos a notícia da morte da criança por falência respiratória, e é nesse momento que o profissional é forçado a aceitar suas limitações em termos profissionais e pessoais.

É importante ressaltar que mesmo enquanto profissional, portando seu arcabouço teórico, metodológico e técnico esses aspectos não o afastam de sua condição humana, e cada individuo deve encontrar sua maneira de expressar a dor de suas perdas. Naturalizar a dor diante de uma perda como essa pode ser muito perigoso, pode favorecer uma politica de atendimento fria e distante, afastando o profissional do feeling necessário para compreender e priorizar as problemáticas latentes de cada indivíduo, impedindo-o de ser pleno em sua atuação.

Além de elaborar seu próprio luto, é primordial que o psicólogo forneça apoio a família, proporcionando um acolhimento adequado e especializado, além de um reforço dos vínculos e da rede de apoio familiar, para que a superação do luto possa ser mais provável e menos "devastadora", evitando, dessa forma, o luto patológico e suas previsíveis 
consequências físicas e emocionais (Medeiros e Lustosa 2011).

José está em estágio avançado da sua patologia, ainda deambula, mas com bastante dificuldade, se recusa a participar de muitas brincadeiras para não ter que enfrentar suas fragilidades ao executá-las, isso limita a atuação do profissional de psicologia no processo de reabilitação uma vez que o universo lúdico é a principal ferramenta nesse processo, no entanto esse mesmo comportamento deixa visível seu estado emocional nos possibilitando uma ponte até o problema latente, suas questões emocionais, e que estas também necessitam de reabilitação pois interferem na política de enfrentamento da criança diante da sua doença, deixando complexo o processo de reabilitação física e intelectual da mesma. Jose apresenta quadros lábeis emocionalmente, irritação e descontroles, comportamento agressivo e ofensivo são suas principais ferramentas no momento de gerar escape para suas dores psicológicas diante de sua condição física. A criança mora com os pais e já perdeu dois tios maternos pela mesma doença e convive com outro tio materno, o terceiro, a ter a mesma condição genética, no entanto em um nível mais avançado, o que não favorece sua auto percepção.

José vive a saga dolorosa de conviver com a Distrofia Muscular de
Duchenne, essa condição tem permitido uma confusão de sensações, devido ao fato de ser algo vívido em sua família, os cuidadores envolvidos demonstram uma inconformidade ímpar em relação ao processo da criança e a mesma é criada com mimos e permissividade, esse comportamento dos cuidadores dificulta o tratamento, permitindo que a criança seja voluntariosa e resistente ao processo de reabilitação, que visa na realidade manter uma qualidade de vida favorável diante de suas dificuldades mas sem muito sucesso uma vez que Jose só faz o que tem vontade e quando quer.

O comportamento de José exige que a psicologia seja atuante, que além de acolher suas dores, o ajude a elaborá-la e trabalhar sua relação com a doença, além de adotar uma conduta pontual e firme de orientação aos pais, incluindo a elaboração do luto por parte dos familiares e da própria criança diante das perdas que o adoecimento tem lhe proporcionado. Essa abordagem permite uma melhor elaboração das condições necessárias para que o processo de neuro estimulação seja eficaz e cumpra seu propósito dentro dos limites que a condição genética de José permite.

$\mathrm{O}$ profissional precisa ter sensibilidade de perceber o que de fato é necessário ser trabalhado em cada caso e que a conduta do neuropsicólogo precisa 
favorecer todas as esferas do individuo, pois como um ser global, precisa ser compreendido em seus aspectos físicos, cognitivos, comportamentais e emocionais e cada parte dessas se relaciona para formar um todo, complexo, que chamamos de SER, ser humano, e que independente da minha conduta enquanto profissional, abordagem de atuação ou política profissional, esse status não anula o meu SER, e que este é determinante na minha atuação enquanto psicólogo, pois não nos impede de fazer ciência, na verdade nos impulsiona a fazê-la.

\section{Considerações Finais}

Durante os atendimentos foi possível entender como a psicologia é rica em sua atuação, repleta de saberes que se agregam, mas não despersonalizam sua essência maior, a escuta, proporcionam ao profissional um viés criativo mesmo diante de um processo progressivo que culminará na morte maior do paciente, mas que intensifica com destreza uma política típica da profissão, mesmo diante das perdas, como alguns possam chamar, ou fechamento dos ciclos da vida como outros acreditam, essa ciência preza pela qualidade de vida, independente do processo ou condição salutar de cada paciente ou que circunstancias sua vida se apresente. A condição de cada paciente relatada possibilita vislumbrar a vivencia do profissional da psicologia diante da sua prática, que apesar de teórica e metodológica como deve proceder sua atuação, é importante destacar que esse fato não inviabiliza sua condição humana e como tal, necessita dos aspectos emocionais que compõe o comportamento pessoal de cada ser humano para nortear sua conduta e dosar o teor técnico da profissão.

Negligenciar esse aspecto da natureza humana é negar a própria ciência a qual nos referimos hoje e que se encontra em franca expansão, que é a neurologia e que tem contribuído de maneira ímpar para o desenvolvimento epistemológico de diversos saberes. A dinâmica de vida de cada paciente acompanhado em seu processo de adoecimento permite que o profissional tenha que lidar com uma realidade pouco remediável, e confrontar o paciente com suas perdas e as perdas do próprio psicólogo ao lidar com um processo de reabilitação que não reabilita e nem se mantem, o recursos acabam ficando escassos e o profissional embora criativo precisa respeitar o limite de cada indivíduo e muitas vezes precisa ampliar a atuação da sua melhor ferramenta de trabalho, a escuta, proporcionando momentos de aceitação e acolhimento ao sofrimento do paciente e dos seus cuidadores. 


\section{Referências}

Beaud, S., Weber, F. (1998). Guide de l'enquête de terrain: produire et analyser des données ethnographiques. Paris: La Découverte.

Cagnin, S. (2010). A pesquisa em neuropsicologia: desenvolvimento histórico, questões teóricas e metodológicas. Psicologia em Pesquisa, 4(2), 118-134.

Callegaro, M. M., Landeira-Fernandez, J. (2007). Pesquisas em neurociência e suas implicações na prática psicoterápica. Psicoterapias: abordagens atuais, 851-872.

Imanishi, H. A., \& Silva, L. L. D. (2016). Despersonalização nos hospitais: o estádio do espelho como operador teórico. Revista da SBPH, 19(1), 41-56.

Kovács, M. J. (1992). Morte e desenvolvimento humano. Casa do Psicólogo.

Lorencetti, A., \& Pessuto Simonetti, J. (2005). As estratégias de enfrentamento de pacientes durante $\mathrm{o}$ tratamento de radioterapia. Revista Latino-Americana de Enfermagem, 13(6). doi.org/10.1590/S0104-11692005000600005

Medeiros, L. A.; Lustosa, M. A. (2011). A difícil tarefa de falar sobre morte no hospital. Revista da SBPH, Rio de Janeiro, 14 (2), 203-227.

Torres, L. F. B. et al. (1997) Estudo por microscopia eletrônica em doenças neurodegenerativas na infância. Arquivos de Neuro-Psiquiatria, São Paulo, 5(4) 788794. doi.org/10.1590/S0004-282X1997000500016.

Turato, E. R. Tratado da metodologia da pesquisa clínico-qualitativa. Petrópolis RJ. Editora Vozes, 2003.

A autora:

Thayse Maria Ferreira Dules Silva é graduada em Psicologia pela Universidade Federal de Alagoas (UFAL), Campus Arapiraca, com especialização em Psicopatologia pela Faculdade de Ensino Regional Alternativa (FERA) e em Neuropsicologia Clínica pelo instituto de Neuropsicologia Aplicada (INAP). Tem experiência na área de Psicologia, atuando principalmente nos seguintes temas: Psicologia Clínica, Psicologia Hospitalar (Urgência, Emergência e Oncologia), Avaliação Psicológica e Neuropsicológica, Psicologia Escolar. E-mail: thaysedules@ gmail.com

Recebido em: 17/08/2018.

Aprovado em: 14/10/2018. 